\title{
Resistance to Adenovirally Induced Hyperleptinemia in Rats Comparison of Ventromedial Hypothalamic Lesions and Mutated Leptin Receptors
}

\author{
Kazunori Koyama, ${ }^{\star}$ Michio Shimabukuro, ${ }^{\star}$ Guoxun Chen, ${ }^{\star}$ May-Yun Wang, ${ }^{\star}$ Young Lee, ${ }^{\star}$ Pushpa S. Kalra, ${ }^{\ddagger}$ Michael G. Dube, ${ }^{\ddagger}$ \\ Satya P. Kalra, ${ }^{\ddagger}$ Christopher B. Newgard, ${ }^{\star}$ and Roger H. Unger ${ }^{\star \S}$ \\ * Gifford Laboratories for Diabetes Research, Departments of Internal Medicine and Biochemistry, University of Texas Southwestern \\ Medical Center, Dallas, Texas 75235; ${ }^{\S}$ Veterans Administration Medical Center, Dallas, Texas 75216; and ${ }^{\ddagger}$ Department of Neuroscience, \\ University of Florida, College of Medicine, Gainesville, Florida 32610-0244
}

\begin{abstract}
Leptin regulates appetite and body weight via hypothalamic targets, but it can act directly on cultured pancreatic islets to regulate their fat metabolism. To obtain in vivo evidence that leptin may act peripherally as well as centrally, we compared the effect of adenovirally induced hyperleptinemia on food intake, body weight, and islet fat content in ventromedial hypothalamic-lesioned (VMHL) rats, shamlesioned (SL) controls, and Zucker Diabetic Fatty (ZDF) rats in which the leptin receptor is mutated. Infusion with recombinant adenovirus containing the rat leptin cDNA increased plasma leptin by $\sim 20 \mathrm{ng} / \mathrm{ml}$ in VMHL and ZDF rats but had no effect on their food intake, body weight, or fat tissue weight. Caloric matching of hyperphagic VMHL rats to SL controls did not reduce their resistance to hyperleptinemia. Whereas prediabetic ZDF rats had a fourfold elevation in islet fat, in VMHL rats islet fat was normal and none of them became diabetic. Isolated islets from $\mathrm{ZDF}$ rats were completely resistant to the lipopenic action of leptin, while VMHL islets exhibited $50 \%$ of the normal response; caloric matching of VMHL rats to SL controls increased leptin responsiveness of their islets to $92 \%$ of controls. We conclude that leptin regulation of adipocyte fat requires an intact VMH but that islet fat content is regulated independently of the VMH. (J. Clin. Invest. 1998. 102:728-733.) Key words: leptin resistance $\bullet$ Zucker Diabetic Fatty (ZDF) rats $(f a / f a) \cdot$ adenoviral gene transfer $\bullet$ islets $\bullet$ triglycerides
\end{abstract}

\section{Introduction}

The hypothalamus plays a crucial role in the control of food intake, thermogenesis, and body composition (1-8). The discovery of leptin (3) and neuropeptide Y (NP-Y) (4) have expanded our understanding of the mechanisms involved in hypothalamic obesity. It has been established that the full-

Address correspondence to Roger H. Unger, M.D., Center for Diabetes Research, University of Texas Southwestern Medical Center, 5323 Harry Hines Boulevard, Dallas, TX 75235-8854. Phone: 214648-6742; FAX: 214-648-9191; E-mail: Runger@mednet.SWmed.edu

Received for publication 6 March 1998 and accepted in revised form 10 June 1998.

J. Clin. Invest.

(C) The American Society for Clinical Investigation, Inc. 0021-9738/98/08/0728/06 \$2.00

Volume 102, Number 4, August 1998, 728-733

http://www.jci.org length leptin receptor isoform, OB- $\mathrm{Rb},{ }^{1}$ is preferentially expressed in the ventromedial hypothalamic (VMH) nucleus (5) and that it downregulates the expression of the NP-Y gene, which encodes an appetite-stimulating neuropeptide (6-8). When leptin is deficient, as in $o b / o b$ mice (3), when OB-Rb is defective, as in $d b / d b$ mice $(9,10)$, when all OB-R isoforms are defective, as in the homozygous ( $f a / f a$ ) Zucker Diabetic Fatty (ZDF) rats $(11,12)$, or when the VMH nucleus is ablated (13), hyperphagia and obesity ensue. However, the latter syndrome differs from the three genetically determined syndromes in that the loss of leptin action is presumably confined to the ablated area and, unlike the genetic syndromes, should not involve extrahypothalamic tissues that express the normal OB-R. Furthermore, diabetes, which complicates all three of the genetic forms of obesity, is reported not to occur in VMHlesioned (VMHL) animals (14).

Although an abundance of evidence points to leptin as the principal signal to the hypothalamus for regulation of body composition, leptin also has striking direct extraneural effects on both adipocytes $(15)$ and nonadipocytes $(16,17)$. For example, it lowers the fat content of isolated islets by directly upregulating the mRNA of enzymes of fatty acid oxidation, carnitine palmitoyl transferase-1 (CPT-1) and acyl-CoA oxidase (ACO), and downregulating mRNA of enzymes of lipogenesis, fatty acid synthetase, fatty acyl-CoA synthetase, and glycerol-phosphate acyl transferase (18). There are also in vivo observations consistent with direct leptin action. For example, when ectopic hyperleptinemia is induced by adenoviral transfer of the leptin cDNA into normal lean rats, all visible fat tissue disappears within $1 \mathrm{wk}$ (19) and fat content falls dramatically in nonadipocytes as well (20); the disappearance of fat is accompanied by the same increase in expression of genes encoding enzymes of fatty acid oxidation, CPT-1 and ACO (19), as was observed in vitro.

In an attempt to determine if the rapid generalized fat depletion caused by ectopic hyperleptinemia is entirely mediated by the VMH nucleus, we induced hyperleptinemia by adenoviral leptin gene transfer in a group of VMHL rats. We had expected that hyperphagia, which is clearly the result of the hypothalamic lesion, would be resistant to the ectopic hyperleptinemia; however, given the presumed qualitative and quantitative integrity of the extrahypothalamic leptin receptors, we expected that all

1. Abbreviations used in this paper: AdCMV-leptin, recombinant adenovirus containing the rat leptin cDNA under control of the CMV promoter; AdCMV- $\beta$ gal, recombinant adenovirus containing the bacterial $\beta$-galactosidase gene under control of the CMV promoter; OB-R, leptin receptor; OB-Rb, leptin receptor b isoform; SL, SLlesioned; TG, triglyceride; $\mathrm{VMH}$, ventromedial hypothalamus; VMHL, VMH-lesioned; ZDF, Zucker Diabetic Fatty. 
OB-R-expressing peripheral tissues, including adipocytes, would respond to the hyperleptinemia. This study was designed to test this prediction.

\section{Methods}

VMHL and sham-lesioned controls. This VMHL was performed at the Department of Neuroscience, University of Florida (Gainesville, FL) as approved by the University of Florida Institutional Animal Care and Use Committee, which follows the National Institutes of Health Guide for the Care and Use of Laboratory Animals. Adult Sprague Dawley (HSD-HD; Harlan Sprague-Dawley, Indianapolis, IN) male rats weighing 250-300 g were housed in air-conditioned rooms $\left(22-25^{\circ} \mathrm{C}\right)$ with lights on from $0500-1900 \mathrm{~h}$. Food and water were available ad libitum. Rats were weighed and anesthetized with sodium pentobarbital $(50 \mathrm{mg} / \mathrm{kg}$ i.p.; Abbott Laboratories, North Chicago, IL). The VMH was destroyed bilaterally by the previously described electrolytic lesion procedure (21). Briefly, rats were placed in the stereotaxic instrument and positioned with the nose bar set $3.3 \mathrm{~mm}$ below the interaural line. The electrode, consisting of an insulated stainless steel insect pin with exposed tip, was positioned $2.6 \mathrm{~mm}$ behind the bregma, $0.6 \mathrm{~mm}$ lateral to the midline, and then lowered to the base of the brain and then raised $0.5 \mathrm{~mm}$. A direct anodal current of $2.5 \mathrm{~mA}$ for $15 \mathrm{~s}$ was passed through the electrode aimed at the VMH with a rectal electrode serving as a cathode. For sham-lesioning (SL), the same surgical procedures were performed except that no current was passed. Rats were allowed to recover for approximately 1 wk before any further procedures were undertaken. They were then flown to Dallas.

Animals. Homozygous ( $f a / f a$ ) ZDF-drt rats were bred in our laboratory from $[\mathrm{ZDF} / \mathrm{Drt}-\mathrm{fa}(\mathrm{F} 10)]$ rats purchased from R. Peterson (University of Indiana School of Medicine, Indianapolis, IN). 6- to 7-wk-old male ZDF ( $f a / f a$ ) rats were used in this study. All Sprague Dawley and ZDF ( $f a / f a)$ rats were studied in individual metabolic cages (Nalgene, Rochester, NY), and body weight and food intake were measured daily. Free-feeding rats were on standard chow (model F6-8664; Teklad, Madison, WI) ad libitum and had free access to water. Calorically matched rats received exactly the amount of food consumed by the SL animals.

Leptingene transfer. To induce hyperleptinemia in SL and VMHL rats, recombinant adenovirus containing the rat leptin cDNA (AdCMV-leptin) was prepared as previously described (19). Briefly, a Bam HI- and Xba I-restricted leptin cDNA fragment that includes $60 \mathrm{bp}$ of $5^{\prime}$ untranslated region and $76 \mathrm{bp}$ of $3^{\prime}$ untranslated region was ligated to similarly treated pACCMVpLpA. The resulting plasmid was cotransfected with pJM17 into 293 cells by calcium phosphate/DNA coprecipitation to generate the AdCMV-leptin. Stocks of AdCMV-leptin were amplified and purified as described (22), and then stored at $-70^{\circ} \mathrm{C}$ in phosphate buffer solution with $0.2 \%$ bovine serum albumin and $10 \%$ glycerol at $3 \times 10^{12} \mathrm{pfu} / \mathrm{ml}$. A virus containing the bacterial $\beta$-galactosidase gene under control of the CMV promoter (AdCMV- $\beta$ gal) was prepared and used as described previously (19). $2 \mathrm{ml}$ of AdCMV-leptin or AdCMV-ßgal viruses containing a total of $10^{12}$ pfu was infused into the right cervical vein of unconscious rats under sodium pentobarbital anesthesia $(50 \mathrm{mg} / \mathrm{kg}$, i.p. $)$ over $30 \mathrm{~min}$.

Plasma measurements. Blood samples were collected from the tail vein in capillary tubes coated with ethylenediaminetetraacetic acid. Plasma was stored at $-20^{\circ} \mathrm{C}$. Plasma leptin was assayed by radioimmunoassay using the Linco leptin assay kit (Linco Research, St. Charles, MO), and insulin radioimmunoassay was performed as previously described (19). Plasma glucose was measured by the glucose oxidase method using a glucose analyzer (glucose analyzer II, Beckman, Brea, CA). Plasma free fatty acid levels were determined using a kit from Boehringer Mannheim (Indianapolis, IN). Plasma triglyceride (TG) levels were measured with a TG kit (GPO-Trinder triglyceride kit; Sigma Chemical Co., St. Louis, MO).
Islet isolation and culture. Pancreatic islets were isolated according to the method of Naber et al. (23) with modifications. They were maintained in suspension culture in $60-\mathrm{mm}$ Petri dishes at $37^{\circ} \mathrm{C}$ in a humidified atmosphere of $5 \% \mathrm{CO}_{2}$ and $95 \%$ air (24). The culture medium consisted of RPMI-1640 medium supplemented with $8.0 \mathrm{mM}$ glucose, $10 \%$ fetal bovine serum, $200 \mathrm{U} / \mathrm{ml}$ penicillin, $0.2 \mathrm{mg} / \mathrm{ml}$ streptomycin, and $2 \%$ bovine serum albumin, fraction V (Bayer, Kankakee, IL).

Tissue triglyceride content. After 3 days in culture, islets were washed twice with Hank's balanced salt buffer and suspended in $50 \mu \mathrm{l}$ of buffer ( $2 \mathrm{M} \mathrm{NaCl} / 2 \mathrm{mM}$ EDNA/50 $\mathrm{mM}$ sodium phosphate, $\mathrm{pH}$ 7.4). After sonication, $10 \mu \mathrm{l}$ of the homogenate was mixed with $10 \mu \mathrm{l}$ of tert-butyl alcohol and $5 \mu \mathrm{l}$ of a Triton X-100/methyl alcohol mixture $(1: 1 \mathrm{vol} / \mathrm{vol})$. TG were extracted with $30 \mu \mathrm{l}$ of tert-butyl alcohol and $20 \mu \mathrm{l}$ of a Triton X-104/methyl alcohol mixture (1:1 vol/vol). TG content was measured by GPO-Trinder triglyceride kit. In other tissues, TG was measured by the same technique as described previously (20).

TG content in skeletal muscle and liver was measured as previously described (20).

Statistical analyses. All values shown are expressed as mean \pm SEM. Statistical analysis was performed by two-tailed unpaired Student's $t$ test by one-way analysis of variance.

\section{Results}

Leptin levels. AdCMV-leptin was infused into lean SL rats, obese VMHL rats, and obese ZDF ( $f a / f a)$ rats. As shown in Fig. $1 A$, baseline plasma leptin levels were elevated in VMHL
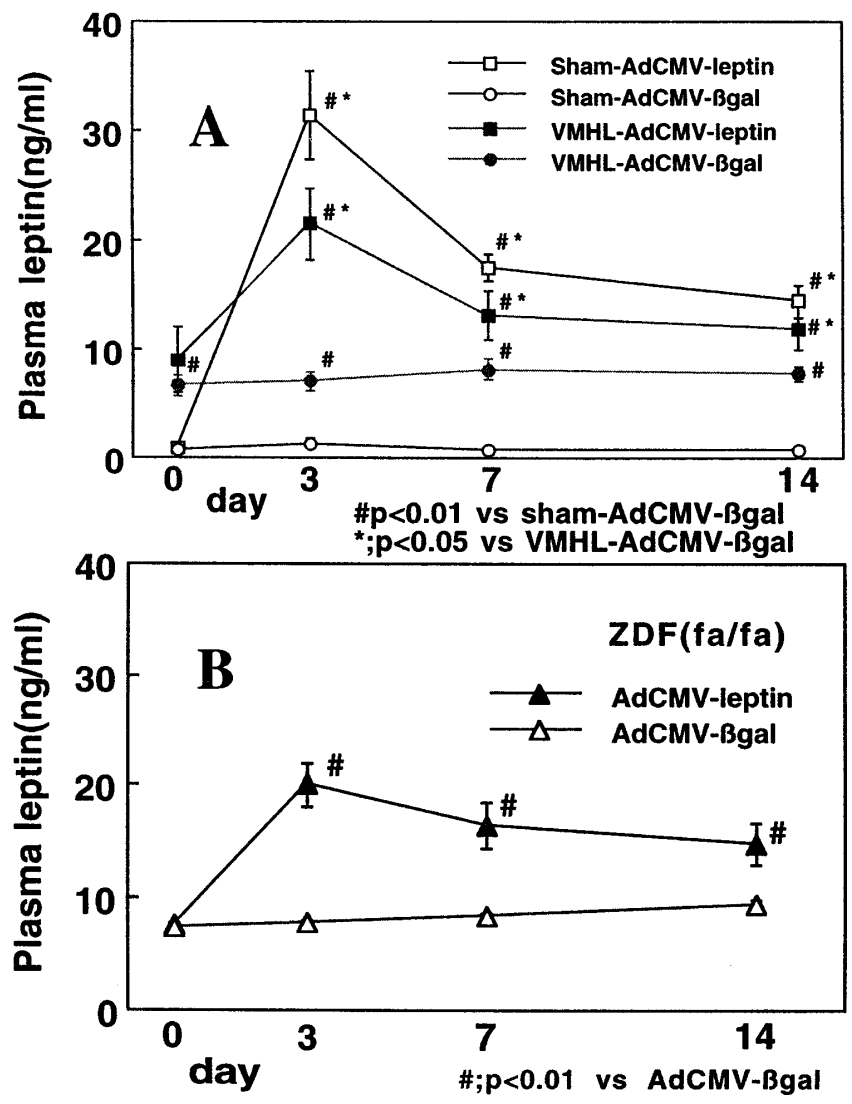

Figure 1. Plasma leptin levels in SL and VMHL Sprague Dawley rats $(A)$, and ZDF ( $f a / f a)$ rats $(B)$ before and 14 days after AdCMV-leptin or AdCMV- $\beta$ gal infusion. Values represent the mean \pm SEM of five experiments. 
and ZDF ( $f a / f a)$ animals, averaging $7.8 \pm 0.7 \mathrm{ng} / \mathrm{ml}$ and $7.6 \pm 0.2$ $\mathrm{ng} / \mathrm{ml}$, respectively, on the day of viral infusion compared with $0.98 \pm 0.1 \mathrm{ng} / \mathrm{nl}$ in SL rats (Fig. 1). In AdCMV-leptin-infused VMHL rats, plasma leptin rose to $21.5 \pm 3.2 \mathrm{ng} / \mathrm{ml}$ on day 3 and declined to $12.0 \pm 2 \mathrm{mg} / \mathrm{ml}$ on day 14 (Fig. $1 A$ ). In ZDF ( $f a / f a)$ rats infused with AdCMV-leptin, plasma leptin reached a peak of $20.3 \pm 2.1 \mathrm{ng} / \mathrm{ml}$ on day 3 and averaged $14.8 \pm 1.9 \mathrm{ng} / \mathrm{ml}$ on day 14 (Fig. 1 B).

Food intake, body weight, and plasma insulin levels. As expected, the food intake and body weight of VMHL rats increased significantly above that of SL rats (Fig. 2, $A$ and $B$ ). While both food intake and body weight were dramatically reduced in SL rats infused with AdCMV-leptin, in the AdCMVleptin-treated VMHL rats, neither food intake nor body weight differed from untreated VMHL controls despite a threefold rise in their previously elevated plasma leptin levels. The weight of epididymal and retroperitoneal fat in VMHL rats was significantly greater than that of SL controls and was not reduced by the increase in hyperleptinemia. Plasma glucose of SL rats infused with AdCMV-leptin declined to $40.3 \pm 2.9 \mathrm{mg} / \mathrm{dl}$ on day 14 , but there was no change in glucose in VMHL rats (Fig. $2 C$ ). As shown in Fig. 2, $D-F$, food intake, body weight, and plasma glucose levels of ZDF $(f a / f a)$ rats were similarly resistant to the effects of the ectopic hyperleptinemia. The lack of a change in either food intake or body weight in the hyperleptinemic VMHL rats indicated that both the anorectic and adipocyte-wasting effects of hyperleptinemia require an intact hypothalamus.

Fasting insulin levels averaged $23 \pm 11.3 \mu \mathrm{U} / \mathrm{ml}$ in VMHL

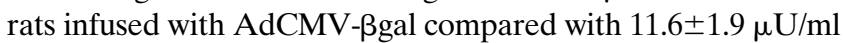
in SL rats infused with AdCMV-ßgal. Hyperleptinemia did not significantly change insulin levels in either group; insulin aver-
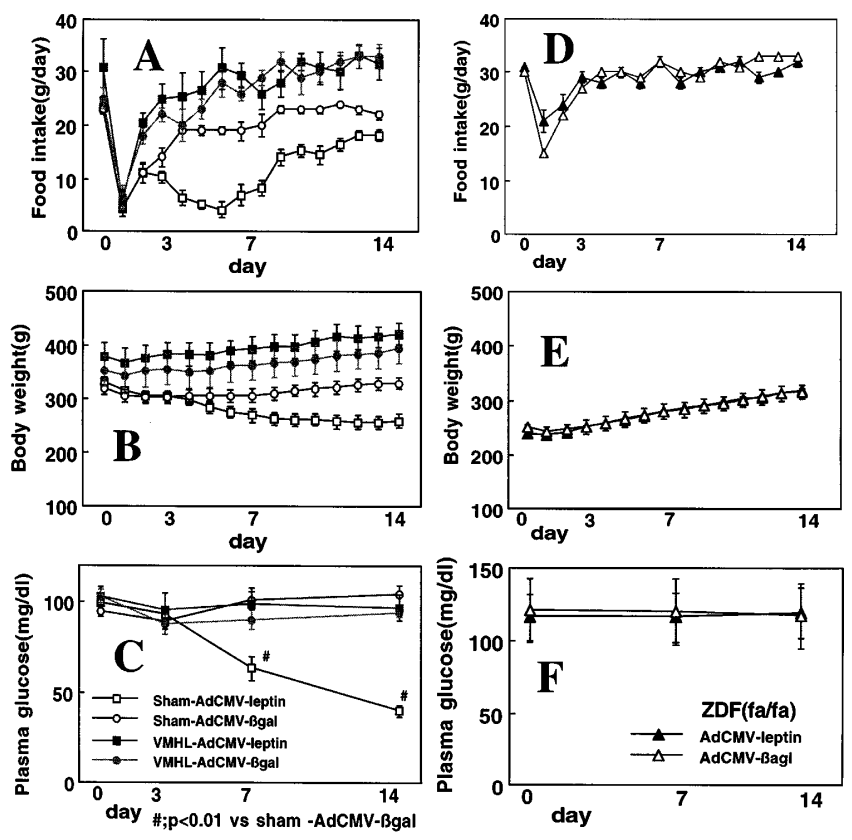

Figure 2. Food intake $(A)$, body weight $(B)$, plasma glucose in SL and VMHL male Sprague Dawley rats $(C)$, and food intake $(D)$, body weight $(E)$, and plasma glucose $(F)$ in ZDF $(f a / f a)$ rats before and $14 \mathrm{~d}$ after AdCMV-leptin or AdCMV-Bgal infusion. Values represent the mean \pm SEM of five experiments. aged 17.7 $\pm 4.9 \mu \mathrm{U} / \mathrm{ml}$ in AdCMV-leptin-infused VMHL rats and $10.2 \pm 2.8 \mu \mathrm{U} / \mathrm{ml}$ in SL rats.

Islet fat content and diabetes. Because the islets of $\mathrm{ZDF}$ ( $f a / f a$ ) rats are resistant to the lipopenic action of leptin, the fat content of their pancreatic islets ranges from 10 to 100 times normal (25). Islet fat exceeds $25-50 \mathrm{ng} /$ islet at the time that diabetes begins, generally between 8-12 wk of age. If the islets of VMHL rats are also resistant to the lipopenic action of leptin, an increase in fat content and the appearance of diabetic abnormalities should have been evident. However, the islet TG content of VMHL rats averaged only $19 \mathrm{ng} /$ islet, not significantly different from that of SL controls, whereas islets of prediabetic ZDF ( $f a / f a$ ) rats of similar age and weight contained over twice as much fat (Fig. 3). This indicates that the islets of VMHL rats must have been far more responsive to leptin in vivo than the islets of $\mathrm{ZDF}(\mathrm{fa} / \mathrm{fa}$ ) rats and almost as responsive as normal islets. However, whereas the genetic leptin resistance of ZDF ( $f a / f a$ ) rats had existed throughout the 7 wk of their life, the VMHL rats had been leptin-resistant for only 3 wk after their surgery. To determine if more prolonged leptin resistance would cause accumulation of islet fat and diabetes, a second group of five VMHL rats was sacrificed $12 \mathrm{wk}$ after $\mathrm{VMH}$ lesioning. The fat content of their islets averaged $21 \mathrm{ng} /$ islet, which is still not significantly above the SL controls.

Consistent with the lack of increased islet fat content in the VMHL rats was the absence of overt diabetes during careful observation up to the age of $20 \mathrm{wk}$. Although none of the rats developed fasting hyperglycemia, their intraperitoneal glucose tolerance test was slightly impaired (Table I). Thus, it appeared that the islets of VMHL rats escape the diabetogenic consequences of leptin resistance, confirming earlier observations by others (14).

Skeletal muscle fat. We had previously reported that in leptin-resistant ZDF ( $f a / f a$ ) rats, the TG content in islets is paralleled by an increase in the TG content of other tissues. In skeletal muscle for example, it rose to $13.8 \mathrm{ng} / \mathrm{g} /$ wet weight, which is almost three times the normal content of $4.1 \pm 1.2 \mathrm{ng} / \mathrm{g} / \mathrm{wet}$ weight (20). This may have been a key factor in their insulin resistance. For this reason, we measured skeletal muscle TG content in VMHL rats. It averaged only $1.1 \pm 0.1 \mathrm{ng} / \mathrm{g} /$ wet

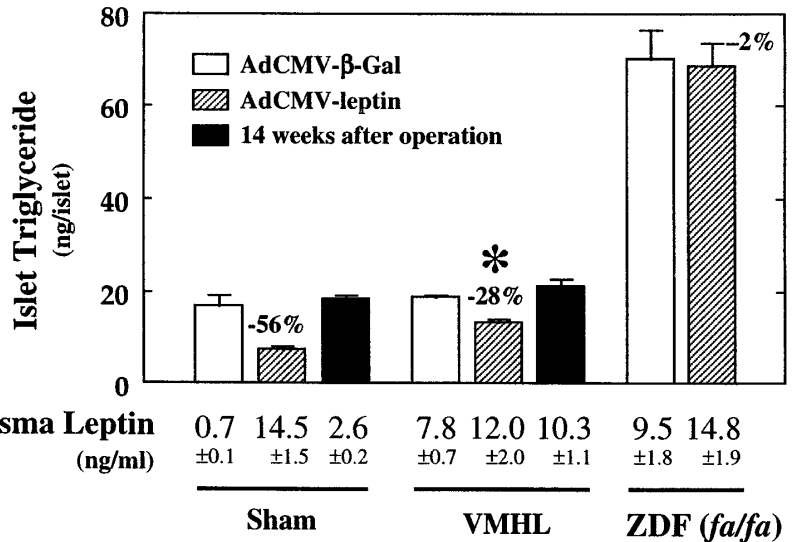

Figure 3. Pancreatic islet triglyceride content of SL and VMHL Sprague Dawley rats and ZDF ( $f a / f a)$ rats $14 \mathrm{~d}$ after AdCMV-leptin or AdCMV- $\beta$ gal infusion and $14 \mathrm{wk}$ after VMHL of Sprague Dawley rats. Values represent the mean \pm SEM of five rats. $* P<0.05$ vs. SL AdCMV-leptin-infused rats. 
Table I. Postprandial Plasma Glucose (PG), Triglyceride (TG), Free Fatty Acids (FFA) Levels, and Glucose Tolerance $64 d$ after SL and VMHL of Male Sprague Dawley Rats

\begin{tabular}{lcc}
\hline & SL & VMHL \\
\hline Plasma & & \\
PG (mg/dl) & $119.5 \pm 4.2$ & $93.8 \pm 3.5^{*}$ \\
TG $(\mathrm{mg} / \mathrm{dl})$ & $90.0 \pm 6.1$ & $175.7 \pm 9.5^{\ddagger}$ \\
FFA (mmol/l) & $0.77 \pm 0.09$ & $2.47 \pm 0.4^{\ddagger}$ \\
Time (h) & & \\
0 & $103.3 \pm 3.9$ & $92.2 \pm 2.4^{*}$ \\
1 & $238.3 \pm 26.5$ & $344.6 \pm 14.0^{\ddagger}$ \\
2 & $161.0 \pm 14.7$ & $287.8 \pm 14.2^{\ddagger}$
\end{tabular}

Data represent the mean \pm SEM of five experiments. Glucose was injected intraperitoneally in a dose of $2 \mathrm{~g} / \mathrm{kg} /$ body weight. $* P<0.05 \mathrm{vs}$. SL; ${ }^{\ddagger} P<0.01$ vs. SL.

weight, about the same as in normal rats made lipopenic by adenoviral leptin gene transfer (20). This low skeletal muscle fat may have provided additional protection against diabetes by increasing insulin sensitivity.

Effect of caloric restriction on in vivo leptin resistance of $V M H L$ rats. Since leptin resistance can be induced in normal rodents by increasing their caloric intake (26), we wished to eliminate any diet-induced impairment of leptin action in VMHL rats. We therefore placed five hyperphagic VMHL rats on a diet calorically matched to that of five SL controls and infused them with AdCMV-leptin. This diet matching had reduced their caloric intake by $28 \%$ prior to the infusion. Their body weight averaged $326 \pm 4.5 \mathrm{~g} 14 \mathrm{~d}$ after the infusion, compared with $421 \pm 19 \mathrm{~g}$ in hyperleptinemic rats without dietary restrictions $(P<0.01)$; however, this was not less than the body weight of calorically matched uninfused VMHL rats (without ectopic hyperleptinemia) and was significantly above the hyperleptinemic SL rats $(260 \pm 13 \mathrm{~g} ; P<0.01)$ (Table II). Thus, caloric restriction in VHML rats failed to reverse or reduce their resistance to the fat-depleting action of ectopic hyperleptinemia. In addition, the weight of their epididymal and retroperitoneal fat depots was no less than that of uninfused VMHL rats (Fig. 4).

Effects of VMHL on leptin action on islets in vitro. Earlier studies had shown that leptin directly lowers TG content in pancreatic islets from normal rats but has no effect in ZDF ( $f a l$ fa) rats with defective leptin receptors. We therefore deter-

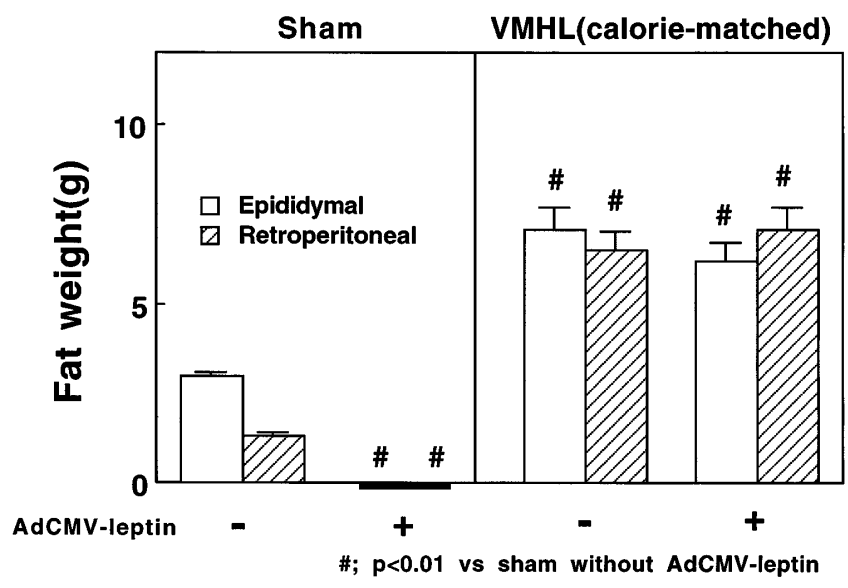

Figure 4. Wet weight of epididymal and retroperitoneal fat of SL and VMHL animals calorically matched to SL Sprague Dawley rats $14 \mathrm{~d}$ after AdCMV-leptin infusion or without infusion. Values represent the mean \pm SEM of five experiments.

mined the in vitro effects of leptin on the TG content of cultured islets from VMHL rats, expecting it to be normal. However, the lipopenic activity of leptin in VMHL rats was only $50 \%$ of SL controls (Fig. 5). To determine if this leptin resistance was due to the ablative procedure itself, or if it was secondary to the increased food intake that follows VMHL, we matched the caloric intake of a group of VMHL rats to that of the SL rats for $2 \mathrm{wk}$ beginning $4 \mathrm{~d}$ after the $\mathrm{VMH}$ ablation. This reduced their caloric intake by $28 \%$. This caloric matching resulted in a twofold increase in sensitivity to the lipopenic action of leptin; the islets were now only $8 \%$ less sensitive than SL controls in terms of lipopenic activity, and this difference was not significant (NS).

\section{Discussion}

This study was designed to determine if obesity produced by ablation of the VMH causes leptin resistance comparable to that observed in ZDF ( $f a / f a)$ rats, in which a Glu $269 \rightarrow$ Pro mutation in the leptin receptor renders tissues completely resistant to the direct lipopenic effects of recombinant leptin (16). Whereas the pancreatic islets of wild-type ZDF $(+/+)$ rats exhibit a $>70 \%$ reduction in fat intake when cultured in the presence of $20 \mathrm{ng} / \mathrm{ml}$ of leptin, in islets from ZDF ( $f a / f a)$ rats the elevated TG content is unresponsive to leptin at any

Table II. Plasma Leptin Levels and Body Weight 14 d after AdCMV-Infusion in SL, VMHL Sprague Dawley Rats Fed Ad Libitum and VMHL Rats Calorically Matched to SL Control Rats

\begin{tabular}{|c|c|c|c|c|c|c|}
\hline & \multicolumn{2}{|c|}{ SL } & \multicolumn{2}{|c|}{ VMHL ad libitum } & \multicolumn{2}{|c|}{ VMHL calorically matched to SL control } \\
\hline & Control & AdCMV-leptin & Control & AdCMV-leptin & Control & AdCMV-leptin \\
\hline Plasma leptin $(n g / m l)$ & $0.98 \pm 0.06$ & $14.5 \pm 1.5^{*}$ & $7.8 \pm 0.7^{*}$ & $12.0 \pm 2.0^{\ddagger}$ & $5.5 \pm 0.7 *$ & $11.4 \pm 1.5^{\S}$ \\
\hline Body weight $(g)$ & $337 \pm 11.5$ & $260 \pm 12.6^{*}$ & $395 \pm 29.0$ & $421 \pm 19.4 *$ & $317 \pm 5.2$ & $326 \pm 4.8$ \\
\hline
\end{tabular}

Data represent the mean \pm SEM of five experiments. ${ }^{*} P<0.01$ vs. SL controls; ${ }^{\ddagger} P<0.05$ vs. VMHL ad libitum controls; ${ }^{\S} P<0.01$ vs. VMHL calorically matched controls. 


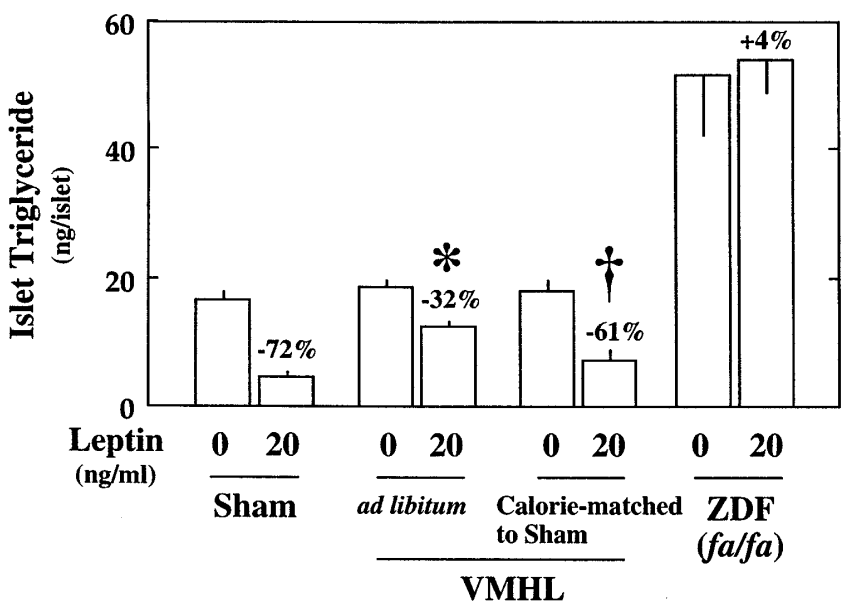

Figure 5. Pancreatic islet triglyceride content of islets of SL, VMHL rats fed ad libitum, VMHL calorically matched to SL male Sprague Dawley rats, and ZDF ( $f a / f a$ ) rats. Islets were cultured for $2 \mathrm{~d}$ with or without $20 \mathrm{ng} / \mathrm{ml}$ leptin. Values represent the mean \pm SEM of five experiments. ${ }^{*} P<0.05$ vs. SL rats with leptin. ${ }^{\dagger} P<0.05$ vs. VMHL rats fed ad libitum.

concentration (16). These findings led us to postulate that leptin acts not only via the hypothalamus but also via direct extrahypothalamic effects on tissues that express normal OB-R. Since it seemed unlikely that a VMH lesion in otherwise normal rats would reduce either the level of expression or functional activity of OB-R in such target tissues, we expected that the hyperphagia of VMHL rats would be resistant to the hyperleptinemia, but that adipocytes would be rapidly depleted of fat, as in normal rats. This was not the case. Despite plasma leptin values threefold above the control VMHL rats, neither body weight nor the weight of epididymal and retroperitoneal fat depots were reduced. Finally, although the normal fat content of their islets suggested that they had been sensitive to leptin in vivo, the direct in vitro lipopenic action of leptin on islets from VMHL rats was only $50 \%$ that of SL controls, indicating a modest level of resistance.

Since increased caloric intake causes leptin resistance (26), we reasoned that the increased caloric intake of the hyperphagic VMHL animals might be inducing peripheral resistance unrelated to the ablation of the hypothalamic nuclei. To test this hypothesis, the caloric intake of the hyperphagic VMHL rats was matched to that of SL controls. This did not reduce either body weight or the weight of epididymal or retroperitoneal fat, but it did improve the lipopenic action of leptin on isolated islets, bringing it to $92 \%$ of SL controls.

In contrast to the complete leptin resistance of ZDF ( $f a / f a)$ rats, in which islet TG content ranges from 10 to 100 times normal, the TG content in islets of VMHL rats was only minimally increased, about $10 \%$ above normal. In addition, skeletal muscle TG content, which is approximately three times normal in ZDF $(f a / f a)$ rats, was subnormal in VMHL rats. This could be construed as evidence of sensitivity to leptin's lipopenic action in vivo. Since the islet cell dysfunction, insulin resistance, and diabetes of ZDF ( $f a / f a$ ) rats has been attributed to the accumulation of tissue fat (25), it was of interest to examine VMHL rats for evidence of diabetes. In VMHL rats, there was no elevation in fasting glucose levels at any time during $90 \mathrm{~d}$ of observation, and their postprandial blood glucose levels, though normal, were lower than in the SL controls (Fig. 2 C). However, the intraperitoneal glucose tolerance test carried out $64 \mathrm{~d}$ after lesioning revealed high levels at 1 and $2 \mathrm{~h}$ (Table I), which may reflect modest insulin resistance and account for the higher insulin levels of the VMHL rats.

The leptin resistance of VMHL rats is manifested by intense hyperphagia and substantial weight gain despite hyperleptinemia. A further increase in hyperleptinemia caused by ectopic leptin expression does not reduce food intake, body weight gain, or weight of fat depots. When the food intake of AdCMVleptin-infused VMHL rats is calorically matched to SL controls to eliminate leptin resistance secondary to high caloric intake, there is still no apparent sensitivity to the ectopic hyperleptinemia in the form of a reduction in body weight or weight of fat depots. Thus, the fat-depleting effect of hyperleptinemia is either mediated by the $\mathrm{VMH}$ through direct neuronal signaling pathways or via a hypothalamic factor that directly or indirectly renders adipocytes sensitive to direct action of leptin.

Islets isolated from VMHL rats on an unrestricted diet were somewhat resistant to the lipopenic action of recombinant leptin; however, when the caloric intake of the VMHL rats was reduced to that of SL controls, there was marked improvement in their sensitivity to the lipopenic action of leptin. This suggests that the peripheral resistance of islets to leptin may in part be the result of the high caloric intake rather than to the loss of central regulatory factors originating from the VMH (27).

Clearly, the VMHL model of obesity differs strikingly from the $f a / f a$ ZDF model. Although the hyperphagia is similar in the two, plasma and tissue lipids are considerably higher in the ZDF rats. Since food intake averages about $30 \mathrm{~g} / \mathrm{d}$ in both groups of rats, it is likely that these differences reflect altered metabolism of the ingested nutrients in the ZDF rats. We have already established that lipogenesis is markedly increased in their tissues (25), and more recently, we have found that expression of the enzymes of lipogenesis such as acetyl CoA carboxylase and fatty acid synthetase (Zhou, Y.-T., Y. Lee, K. Koyama, T. Ferguson, and R.H. Unger, unpublished data) is greatly increased. Since the increased lipogenesis can be reversed by expressing the wild-type leptin receptor in their tissues (28), we speculate that in VMHL rats, overexpression of lipogenic enzymes and thus their lipogenic capacity is constrained by a direct action of the hyperleptinemia on OB-R-expressing tissues. In ZDF rats, by contrast, these tissues are completely unresponsive to the hyperleptinemia, and the lack of any direct leptin action results in a much greater lipogenic capacity.

\section{Acknowledgments}

We thank Shailendra Patel, Ph.D., Asst. Prof., Center for Clinical Nutrition, UTSWMS, for his interest, Kay McCorkle, Tagan Ferguson who performed outstanding technical support, and Tess Perico, who provided excellent secretarial assistance.

This work was supported by Veterans Administration Institutional Research Support grant SMI-821-109 and National Institutes of Health (NIH) grant DK-02700-37, and grants from Novo Nordisk, Copenhagen, and Sankyo, Tokyo (R.H. Unger) and by NIH grants DK-37273 (S.P. Kalra) and NS-32727 (P.S. Kalra). Animal care was in accordance with institutional guidelines.

\section{References}

1. Bray, G.A. 1996. Mechanism for development of genetic and dietary obesity. In Molecular and Genetic Aspects of Obesity. G.A. Bray and D.H. Ryan, 
editors. LSU Press, Baton Rouge, LA. 2-66.

2. Kalra, S.P. 1997. Appetite and body weight regulation: Is it all in the brain? Neuron. 19:227-230.

3. Zang, Y.R., R. Proenca, M. Maffei, M. Barone, L. Leopold, and J.M. Friedman. 1994. Positional cloning of the mouse obese gene and its human homologue. Nature. 372:425-432.

4. Clark, J.T., P.S. Kalra, W.R. Crowley, and S.P. Kalra. 1984. Neuropeptide $\mathrm{Y}$ and human pancreatic polypeptide stimulate feeding behavior in rats. Endocrinology. 115:427-429.

5. Tartaglia, L.A., M. Dembski, X. Weng, N.-H. Deng, J. Culpepper, R. Devos, G.J. Richards, L.A. Campfield, F.T. Clark, J. Deeds, et al. 1995. Identification and expression cloning of leptin receptor, OB-R. Cell. 83:1263-1271.

6. Schwartz, M.W., D.G. Baskin, T.R. Bukowski, J.L. Kuijper, D. Foster, G. Lasser, D.E. Prunkard, D. Porte, Jr., S.C. Woods, R.J. Seeley, et al. 1996. Specifity of leptin action on elevated blood glucose levels and hypothalamic neuropeptide Y gene expression in ob/ob mice. Diabetes. 45:531-535.

7. Xu, B., M.G. Dube, P.S. Kalra, W.G. Farmerie, A. Kaibara, L.L. Moldawer, D. Martin, and S.P. Kalra. 1998. Anorectic effects of the cytokine, ciliary neurotropic factors are mediated by hypothalamic neuropeptide $\mathrm{Y}$ : comparison with leptin. Endocrinology. 139:466-473.

8. Stephens, T.W., M. Basinski, P.K. Bristow, J.M. Bue-Valleskey, S.G. Burgett, L. Craft, J. Hale, J. Hoffman, H.M. Hsiung, A. Kriauciunas, et al. 1995. The role of neuropeptide $\mathrm{Y}$ in the antiobesity action of the obese gene product. Nature. 377:530-532.

9. Lee, G.H., R. Proenca, J.M. Montez, K.M. Carroll, J.G. Darvishzadeh, J.I. Lee, and J.M. Friedman. 1996. Abnormal splicing of the leptin receptor in diabetic mice. Nature. 379:632-635.

10. Chen, H., O. Charlat, L.A. Tartaglia, E.A. Woolf, X. Weng, S.J. Ellis, N.D. Lakey, J. Culpepper, K.J. Moore, R.E. Breitbart, et al. 1996. Evidence that the diabetes gene encodes the leptin receptor: identification of a mutation in the leptin receptor gene in $d b / d b$ mice. Cell. 84:491-495.

11. Phillips, M.S., Q. Liu, H.A. Hammond, V. Dugan, P.J. Hey, C.J. Caskey, and J.F. Hess. 1996. Leptin receptor missense mutation in the fatty Zucker rat. Nat. Genet. 13:18-19.

12. Iida, M., T. Murakami, K. Ishida, A. Mizuno, M. Kuwajima, and K. Shima. 1996. Substitution at codon 269 (glutamine $\rightarrow$ proline) of the leptin receptor (OB-R) cDNA is the only mutation found in the Zucker fatty ( $f a / f a$ ) rat. Biochem. Biophys. Res. Commun. 224:597-604.

13. Satoh, N., Y. Ogawa, G. Katsuura, T. Tsuji, H. Masuzaki, J. Hiraoka, T. Okazaki, M. Tamaki, M. Hayase, Y. Yoshimasa, et al. 1997. Pathophysiological significance of the obese gene product, leptin, in ventromedial hypothalamus (VMH)-lesioned rats: evidence for loss of its satiety in VMH-lesioned rats. Endocrinology. 138:947-954.

14. Bray, G.A., and D.A. York. 1979. Hypothalamic and genetic obesity in experimental animals: an autonomic and endocrine hypothesis. Physiol. Rev. 59:719-782.
15. Bai, Y., S. Zhang, K.-S. Kim, J.-K. Lee, and K.-H. Kim. 1996. Obese gene expression alters the ability of $30 \mathrm{~A} 5$ preadipocytes to respond to lipogenic hormones. J. Biol. Chem. 271:13939-13942.

16. Shimabukuro, M., K. Koyama, G. Chen, M.-Y. Wang, F. Trieu, Y. Lee, C.B. Newgard, and R.H. Unger. 1997. Direct antidiabetic effect of leptin through triglyceride depletion of tissues. Proc. Natl. Acad. Sci. USA. 94:4637-4641.

17. Muoio, D.M., G. Dohn, F.T. Fiedorek, Jr., E.B. Tapscott, and R.A. Coleman. 1997. Leptin directly alters lipid partitioning in skeletal muscle. Diabetes. 48:1360-1363.

18. Zhou, Y.-T., M. Shimabukuro, K. Koyama, Y. Lee, M.-Y. Wang, F. Trieu, C.B. Newgard, and R.H. Unger. 1997. Induction by leptin of uncoupling protein-2 and enzymes of fatty acid oxidation. Proc. Natl. Acad. Sci. USA. 94: 6386-6390.

19. Chen, G., K. Koyama, X. Yuan, Y. Lee, Y.-T. Zhou, R. O’Doherty, C.B. Newgard, and R.H. Unger. 1997. Disappearance of body fat in normal rats induced by adenovirus-mediated leptin gene therapy. Proc. Natl. Acad. Sci. USA. 93:14795-14799.

20. Koyama, K., G. Chen, Y. Lee, C.B. Newgard, and R.H. Unger. 1997. Tissue triglycerides, insulin resistance, and insulin production: implications for hyperinsulinemia of obesity. Am. J. Physiol. 273 (Endocrinol. Metab. 36):E708E713.

21. Dube, M.G., P.S. Kalra, W.R. Crowley, and S.P. Kalra. 1995. Evidence of a physiological role for neuropeptide $\mathrm{Y}$ in ventromedial hypothalamic lesion induced hyperphagia. Brain Res. 690:275-278.

22. Becker, T.C., R.J. Noel, W.S. Coats, A.M. Gomez-Foix, T. Alam, R.D. Gerard, and C.B. Newgard. 1994. Use of recombinant adenovirus for metabolic engineering of mammalian cells. Methods Cell Biol. 43:161-189.

23. Naber, S.P., J.M. McDonald, L. Jarett, M.L. McDaniel, C.W. Ludvigsen, and P.E. Lacy. 1980. Preliminary characterization of calcium binding in isletcell plasma membranes. Diabetologia. 19:439-444.

24. Milburn, J.L., H. Hirose, Y.-H. Lee, Y. Nagasawa, A. Ogawa, M. Ohneda, H. Beltrandel Rio, C.B. Newgard, J.H. Johnson, and R.H. Unger. 1995. Pancreatic $\beta$-cells in obesity: evidence for induction of functional, morphologic and metabolic abnormalities by increased long-chain fatty acids. $J$. Biol. Chem. 170:1295-1299.

25. Lee, Y., H. Hirose, Y.-T. Zhou, V. Esser, J.D. McGarry, and R.H. Unger. 1997. Increased lipogenic capacity of the islets of obese rats. Diabetes. 46 408-413.

26. Frederich, R.C., A. Hamann, S. Anderson, B. Lollmann, B.B. Lowell, and J.S. Flier. 1995. Leptin levels reflect body lipid content in mice: evidence for diet-induced resistance to leptin action. Nat. Med. 1:1311-1314.

27. Woods, S.C., R.J. Seely, D. Porte, Jr., and M.W. Schwartz. 1998. Signals that regulate food intake and energy homeostasis. Science. 280:1378-1383.

28. Wang, M.-Y., K. Koyama, M. Shimabukuro, C.B. Newgard, and R.H. Unger. 1998. OB-Rb gene transfer to leptin-resistant islets reverses diabetogenic phenotype. Proc. Natl. Acad. Sci. USA. 95:714-718. 